\title{
Correlation Between Helicobacter pylori Infection, Gastric Diseases and Life Habits Among Patients Treated at a University Hospital in Southeast Brazil
}

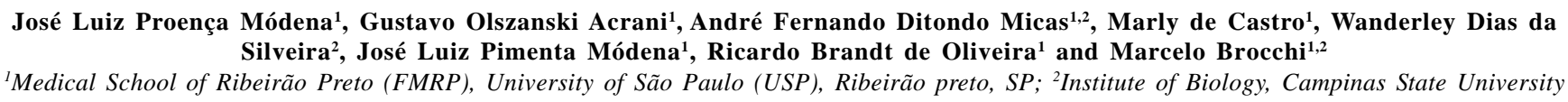
(UNICAMP), Campinas, SP, Brazil

\begin{abstract}
Helicobacter pylori is considered a significant agent in the development of various gastric diseases. However, the diseases caused by this bacterium are known as being multi-factorial, with the genotype, immune system and life habits of the host playing important roles in the establishment of the clinical outcome. Also, $H$. pylori exhibit a high degree of genetic variability, contributing to the complexity of the host-pathogen relationship. These observations, considered together with the widely-varying origins and social habits of the Brazilian population, lead us to speculate about the influence of these life habits on $\boldsymbol{H}$. pylori infection and the clinical outcome. Therefore, in this study we evaluated the relationship between $H$. pylori infection and certain diseases in 172 patients treated at the Hospital das Clínicas of Ribeirão Preto (HCRP), Brazil, taking into account their different life habits, such as nonsteroidal anti-inflammatory drugs and alcohol ingestion, and smoking habit. Our analysis indicated that $\boldsymbol{H}$. pylori infection is not affected by any of the life habits evaluated but is associated with the development of peptic ulcers (gastric and duodenal ulcer) and inverse correlate with gastroesophageal reflux disease (GERD). No correlation was found between the infection with this bacterium and gastritis or intestinal metaplasia. However, gastritis and erosive gastritis were directly correlated with non-steroidal anti-inflammatory drugs (NSAID) ingestion. Moreover, ingestion of alcohol beverages exhibited a protective effect on gastritis development in men. Our data also indicated that to achieve reliable detection of this bacterium in biopsies, two or three detection methods should be used. Key-Words: Helicobacter pylori, duodenal ulcer, gastric ulcer, gastritis, life habits.
\end{abstract}

Helicobacter pylori are spiral, microaerophilic, Gramnegative bacteria exhibiting four to six unipolar-sheathed flagella. However, when cultivated on solid medium, H. pylori assume a rod-like shape [revised by 1 ]. This bacterium infects the gastric mucosa of more than $50 \%$ of people in the world, being recognized as one of the most common human pathogen [2]. Colonization by this microorganism induces a chronic gastric inflammation, which can progress to a variety of diseases, from gastritis to peptic ulcer (gastric ulcer and duodenal ulcer), gastric cancer and the associated mucous lymphomas (MALT lymphoma), as reviewed by Blaser and Atherton [3].

Although $H$. pylori infection is a significant step in the development of gastric diseases, other factors, such as genotype, immunological response and life habits of the host are of great importance in the establishment of these diseases. This is evident from the fact that only about $10 \%$ of people infected with this organism become sick [4] and that the prevalence of $H$. pylori in patients with peptic ulcer varies from one area to another $[5,6]$. Moreover, close correlation was observed between the eradication of this microorganism and the establishment of the so-called gastroesophageal reflux disease (GERD) [3,7], suggesting that $H$. pylori could be in a symbiotic relationship to Homo sapiens.

Received on 21 August 2006; revised 15 December 2006.

Address for correspondence: Dr. Marcelo Brocchi. Departamento de Microbiologia e Imunologia, Instituto de Biologia, UNICAMP, Cidade Universitária “Zeferino Vaz”. Campinas, São Paulo, Brazil. Zip code: 13083 - 862. FAX: (55-19) 3521-6276. Phone: (55-19) 3521-6223. E-mail: mbrocchi@unicamp.br.

The Brazilian Journal of Infectious Diseases 2007;11(1):89-95. (C) 2007 by The Brazilian Journal of Infectious Diseases and Contexto Publishing. All rights reserved.
The complexity of the host-pathogen relationship for $H$. pylori and humans is also a consequence of the enormous genetic diversity exhibited by this bacterium. This characteristic became evident when the genome of several strains was compared [8-10]. The genetic diversity revealed led some authors to consider $H$. pylori as a quasi-species [2], which may be explained by a high rate of horizontal gene transfer occurring between different isolates, and by the enormous plasticity of its genome, which is prone to recombine and has a high mutation rate [8].

In light of these observations and the great diversity and intermixing of the ethnic groups in Brazil, as observed in the Ribeirão Preto area, we examined the association of this bacterium with the gastric diseases commonly related to its presence. Thus, the objective of this study was to evaluate the relationship between $H$. pylori infection and clinical outcomes, like gastritis, gastric and duodenal ulcer, intestinal metaplasia and gastroesophageal reflux disease (GERD) in patients attending the University teaching hospital of FMRP, USP (HCRP), taking into account their different life habits, such as non-steroidal anti-inflammatory drugs and alcohol ingestion, and smoking habit.

\section{Materials and Methods}

Collection of Biopsy Samples from Patients

This was a retrospective study conducted with 172 patients who attended the Endoscopy Service of the HCRP from July 2000 to September 2003, and presented any type of symptoms varying from disturbances of the upper gastrointestinal tract, such as abdominal pain, heartburn, upper gastrointestinal bleeding to nausea and vomiting. A history of taking nonsteroidal anti-inflammatory drugs (NSAID), as well as smoking 
and drinking habits, was documented. The rules for patients inclusion in the study were the smoke of at least one cigar a day, the ingestion of at least one pill of NSAID a week, or more than $250 \mathrm{~mL}$ of alcohol beverages a day, for at least three months before the procedure for $H$. pylori detection. The patients were also divided in their ethnic groups (Caucasian, Afro-descendant, Mulatto and Asians) by their skin colors. The ethics committee of HCRP approved the study protocol. The patients gave written informed consent to be included in the study. Our research followed the tenets of the Declaration of Helsinki.

Patients were evaluated clinically and gastrointestinal signs and symptoms were recorded. Upper gastrointestinal endoscopy was carried out under conscious sedation with midazolam (average $1 \mathrm{mg}$ ) and meperidine (average $50 \mathrm{mg}$ ) administered intravenously in doses that varied from patient to patient, according to the procedure. Three biopsies from the corpus of the stomach and three from the antrum of the stomach were taken from each patient with flexible biopsy forceps (5mM cups - Endo-flex® $\mathrm{GmbH}$ ).

\section{Patient Stratification}

Patient diseases were stratified into gastritis, peptic ulcer disease (PUD), intestinal metaplasia (IM), and gastroesophageal reflux disease (GERD). PUD was diagnosed on the basis of endoscopy findings and was further stratified into gastric (GU) or duodenal ulcer (DU). GERD diagnosis was made in conformity with accepted criteria [11]. Gastritis and intestinal metaplasia were diagnosed on the basis of positive histological findings and absence of peptic ulcer disease. Patients with erosive gastritis were also recorded.

\section{The Urease Test (CLOtest $\left.{ }^{\circledR}\right)$ :}

One biopsy from the antrum and another from the stomach were used for the detection of $H$. pylori by the urease test [12].

\section{Histological Examination}

The second pair of biopsies were immediately fixed in 10\% formalin and taken to the Pathological Anatomy Service of the HCRP, where they were embedded in paraffin blocks, sectioned and stained in haematoxylin and eosin (HE), for conventional histological examination and disease diagnosis and to detect bacteria that resembled $H$. pylori by optical microscopy (magnification of 1000X).

\section{Cultivation of $H$. pylori}

The last pair of biopsies were placed in saline solution ( $\mathrm{NaCl} 0.85 \%$ ) and taken in less than 4 hours to the Genomics and Bacterial Molecular Biology Laboratory at FMRP, where they were seeded on 3.9\% Columbia agar medium (Oxoid), enriched with $5 \%$ horse blood, $0.2 \% \beta$-cyclodextrin (Sigma), $100 \mu \mathrm{g} / \mathrm{mL}$ cycloheximide (Sigma), $5 \mu \mathrm{g} / \mathrm{mL}$ vancomycin (Ariston), and $8 \mu \mathrm{g} / \mathrm{mL}$ amphotericin B (Bristol-Myers Squibb). They were cultured for five days under microaerophilic condition (5\%-6\% $\mathrm{O}_{2}, 8 \%-10 \% \mathrm{CO}_{2}, 80 \%-85 \% \mathrm{~N}_{2}$, and a relative humidity of at least $95 \%)$. Bacterial growth was confirmed as being $H$. pylori by microscopic examination of slides after Gram staining, and by the urease, catalase, and oxidase tests [12].

\section{Statistical Analysis}

Data were analyzed by the chi-squared test with Yates' correlation or the Fisher exact test. Logistic regression was performed for the adjustment of the age of the patients with the other variables. The hypothesis being tested was that the proportions of two patient groups were (or were not) significantly different among $H$. pylori positive and negative cases at the $5 \%$ level $(\alpha=0.05)$. Thus, statistical significance was accepted for $\mathrm{p} \leq 0.05$. The analyses were run in the SAS System for Windows (Statistical Analysis System), version 8.2.

\section{Results}

Of the 172 studied patients, 147 (85\%) presented H. pylori at some time during the study (Tables 1 and 2). Of these 147 patients, 121 (82\%) showed this microorganism in the gastric mucosa at the time of the endoscopic examination, detected by at least one of the methods used to detect the bacterium. The remaining 26 patients were negative in the culture, urease and histological tests, but they had presented a positive diagnosis a few weeks before examination and were undergoing treatment for $\mathrm{H}$. pylori eradication.

The detection of $H$. pylori onto artificial culture medium [sensitivity: 78\%; specificity: 89\%; PPV (Positive predictive value): $94 \%$; NPV (negative predictive value): 67\%; prevalence: 67\%; accuracy: 82\%] was the least efficient method, while the urease [(Clotest $\left.{ }^{\circledR}\right)$; sensitivity: $90 \%$; specificity: $85 \%$; PPV: 92\%; NPV: $82 \%$; prevalence: $65 \%$; accuracy: $88 \%$ ] test was the most. Out of 121 patients colonized by $H$. pylori, it was isolated in culture medium from 96 (80\%), while 110 patients (91\%) were positive for the presumptive presence of this bacterium by the Clotest ${ }^{\circledR}$. The histological analysis of gastric biopsies (sensitivity: 83\%; specificity: 96\%; PPV: 92\%; NPV: 71\%; prevalence: $69 \%$; accuracy: $87 \%$ ) detected $H$. pylori in 100 patients (83\%). Although the Clotest ${ }^{\circledR}$ was the most efficient method of detection, 11 patients that were positive for $H$. pylori in at least one of the other methods were negative in the Clotest ${ }^{\circledR}$. Moreover, in 17 patients the $H$. pylori detection was positive in only one of the tests used. Additionally, only in 81 patients (67\%), the three methods of diagnosis were in agreement (Figure 1 ).

No significant difference was observed among the $H$. pylori positive and $H$. pylori negative patients with respect to gender (Table 1$)$. Ninety-six patients (56\%) were aged between 40 and 59 years, but this pathogen did not show higher prevalence at any age (Table 1). The prevalence of $H$. pylori was very high in all four ethnic groups analyzed (Table 1 ), and no significant differences (for $\mathrm{p}<0.05$ ) were observed when these proportions were compared. 
Table 1. H. pylori prevalence in 172 patients categorized by gender, age, ethnic groups and life habits

\begin{tabular}{|c|c|c|c|c|}
\hline \multirow[b]{2}{*}{ Characteristic } & \multirow[b]{2}{*}{$\mathbf{N}(\%$ total $)$} & \multicolumn{3}{|c|}{$\chi^{2}$ Test with Yates } \\
\hline & & H. pylori n1 (\%)** & No H. pylori n2 (\%)** & Significance \\
\hline \multicolumn{5}{|l|}{ Gender } \\
\hline Male & $83(48 \%)$ & 68 (82\%) & $15(18 \%)$ & $\mathrm{p}=0.29 ; \chi^{2}=1.11$ \\
\hline Female & 89 (52\%) & 79 (89\%) & $10(11 \%)$ & not significant* \\
\hline \multicolumn{5}{|l|}{ Age } \\
\hline $10-19$ & $4(2 \%)$ & $4(100 \%)$ & $0(0 \%)$ & $\mathrm{p}=0.83 ; \chi^{2}=1.47$ \\
\hline $20-39$ & 36 (21\%) & 32 (89\%) & $4(11 \%)$ & not significant* \\
\hline $40-59$ & $96(56 \%)$ & 81 (84\%) & $15(16 \%)$ & \\
\hline $60-59$ & 35 (20\%) & $29(83 \%)$ & $6(17 \%)$ & \\
\hline $80-81$ & $1(1 \%)$ & $1(100 \%)$ & $0(0 \%)$ & \\
\hline \multicolumn{5}{|l|}{ Ethnic groups } \\
\hline Caucasians & 138 (80\%) & 114 (83\%) & 24 (17\%) & $p=0.20 ; \chi^{2}=4.7$ \\
\hline Afro-descendants & $9(5 \%)$ & $9(100 \%)$ & $0(0 \%)$ & not significant* \\
\hline Mulattos & 23 (14\%) & 22 (96\%) & $1(4 \%)$ & \\
\hline Asians & $2(1 \%)$ & $2(100 \%)$ & $0(0 \%)$ & \\
\hline \multicolumn{5}{|l|}{ Habits } \\
\hline Smokers & 63 (37\%) & 53 (84\%) & $10(16 \%)$ & $p=0.87 ; \chi^{2}=0.03$ \\
\hline Non smokers & 109 (63\%) & $94(86 \%)$ & $15(14 \%)$ & not significant* \\
\hline Drinkers & 57 (33\%) & 48 (84\%) & $9(16 \%)$ & $p=0.92 ; \chi^{2}=0.009$ \\
\hline Non drinkers & 115 (67\%) & 99 (86\%) & $15(14 \%)$ & not significant* \\
\hline NSAID use & $39(23 \%)$ & 32 (82\%) & $7(18 \%)$ & $\mathrm{p}=0.67 ; \chi^{2}=0.19$ \\
\hline No NSAID & 133 (77\%) & 115 (86\%) & $18(14 \%)$ & not significant* \\
\hline Total & $172(100 \%)$ & 147 (85\%) & 25 (15\%) & 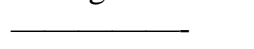 \\
\hline
\end{tabular}

$\mathrm{N}$ : total number of patients with a certain characteristic.; n1: number of $H$. pylori positive patients with a certain characteristic.; n2: number of $H$. pylori negative patients with a certain characteristic.; *: Statistical difference was accepted for $\mathrm{p} \leq 0.05$.; **: Percentage of patients with a certain characteristic that are $H$. pylori positive or negative.

Figure 1. Detection of $H$. pylori by using the methods of isolation of the microorganism in culture medium, histological analysis of gastric biopsies and detection of the urease enzyme (Clotest $\left.{ }^{\circledR}\right)$ in 121 patients attended in the Endoscope Service of the HCRP from July 2000 to September 2003.

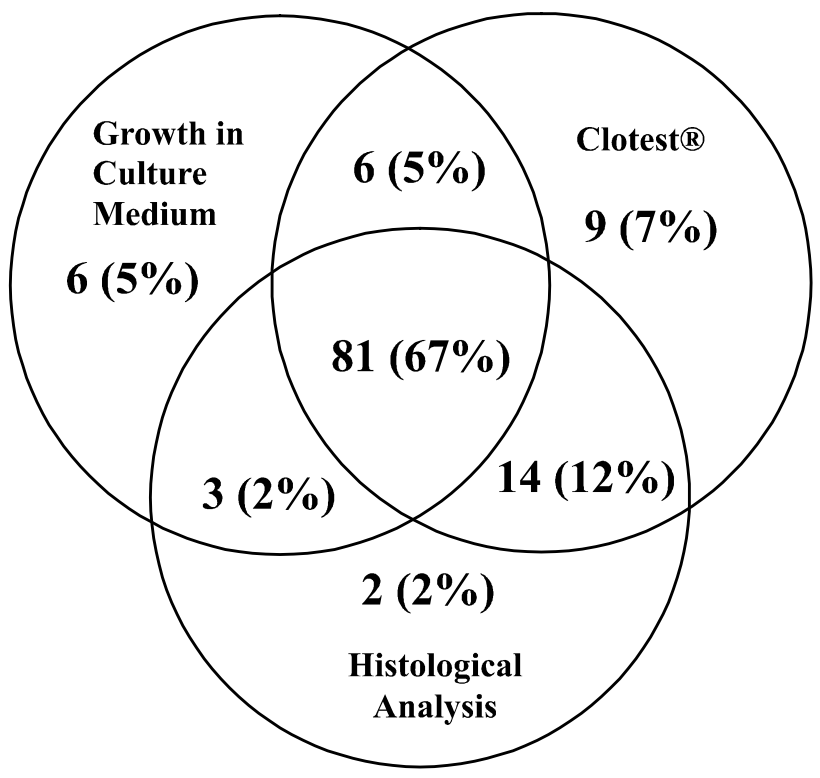

www.bjid.com.br 
Regarding the history of non-steroidal anti-inflammatory drug (NSAID) taking and smoking and drinking habits, no significant difference was observed with respect to the prevalence of $H$. pylori (Table 1 ).

When the clinical outcomes were analyzed, a higher prevalence of duodenal ulcer ( $p=0.0018$ and $\chi^{2}=11.32$ ), gastric ulcer ( $\mathrm{p}=0.0022$ and $\left.\chi^{2}=10.87\right)$ and peptic ulcer disease $(\mathrm{p}<$ 0.0001 and $\chi^{2}=35.35$ ) were noted in patients with $H$. pylori than in $H$. pylori-negative patients (Table 2). These results indicated a correlation between the presence of this microorganism and these pathologies. The high proportion of patients without ulcerous diseases that did not show this pathogen, compared to patients hosting $H$. pylori, was also relevant, being the difference statistically very significant ( $p<0.0001$ ), which strongly corroborates the proposed inverse correlation. Gastritis was more frequent in patients with $H$. pylori but the proportions were not statistically significant (Table 2).

$H$. pylori was not significantly more prevalent in patients with intestinal metaplasic cells than in those without this disease $\left(p=0.19\right.$ and $\left.\chi^{2}=1.26\right)$. However, all patients with intestinal metaplasic cells were colonized by $H$. pylori, and $10 \%$ of the $H$. pylori-positive patients had this disease, suggesting that a correlation between this bacterium and the genesis of this pathology could exist.

In relation to the gastroesophageal reflux disease (GERD), a larger proportion of patients with this disease was observed in $H$. pylori negative patients ( $p=0.001$ and $\chi^{2}=12.46$ ), showing that this bacterium might protect patients from the development of severe GERD (Table 2).

A higher proportion of patients without any pathology, in other words, with a normal stomach mucosa, was observed in people that did not possess $H$. pylori in their stomachs $(\mathrm{p}=$ 0.0037 and $\chi^{2}=9.61$ ).

The possible association between life habits or ethnic groups and the clinical outcomes was also evaluated. The only association found to be statistically significant was between NSAID taking and erosive gastritis ( $p=0.0003$ ).

Logistic regression was performed for the adjustment of the age of the patients with the other variables to corroborate or not the associations found in the individual analyzes by the chi-squared test. The correlation between gastric ulcer ( $p$ $=0.0065$ and odds ratio 17.09), duodenal ulcer $(\mathrm{p}=0.0149$ and odds ratio 12.71) and peptic ulcer ( $\mathrm{p}<0.00001$ and odds ratio 36.70) diseases with the $H$. pylori infection were all undoubtedly confirmed by these analyzes. Patients with $H$. pylori infection exhibited an increasing risk of 17.09, 12.71 and 36.70 folds to develop gastric, duodenal and peptic ulcer diseases, respectively. The infection by $H$. pylori protects individuals against GERD development $(\mathrm{p}=0.0018$ and odds ratio 0.23$)$. The risk to gastric $(p=0.0001$ and odds ratio 1.055$)$ or duodenal ulcer ( $\mathrm{p}=0.028$ and odds ratio 2.063 ), as well as the presence of metaplasic cells ( $p=0.0153$ and odds ratio 1.052) development exhibited a tendency to increase with age. The ingestion of alcoholic beverages increased in 10 folds the risk to peptic ulcer development in males infected by $H$. pylori ( $\mathrm{p}=0.0183$ and odds ratio 10.17). The correlation between the absence of $\mathrm{H}$. pylori and patients with normal mucosa ( $p=0.0022$ and odds ratio 0.11 ) was also confirmed. The ingestion of NSAID was associated with gastritis $(\mathrm{p}=$ 0.0412 and odds ratio 2.344 ) and particularly with erosive gastritis $(p=0.0027$ and odds ratio $>100)$. The smoking habit ( $p=0.0354$ and odds ratio 8.926) was also associated with gastritis development. On the other hand, the ingestion of alcoholic beverages by males was inversely associated with this disease $(p=0.0244$ and odds ratio 0.0244).

\section{Discussion}

Eighty-five per cent of the patients herein studied were found to be infected with $H$. pylori (Tables 1 and 2), in agreement with other studies conducted in developing countries like Brazil. For example, Bani-Hani and Hammouri [13] reported a rate of human $H$. pylori infection of $82 \%$ in Jordanian patients. In Brazil, rates of about $78 \%$ have been previously found $[14,15]$. However, the rate of $H$. pylori infection presented here is probably higher than normal, because only symptomatic patients were tested.

The culturing of $H$. pylori has already been described [16] as the least efficient of the invasive methods for the detection of this bacterium, owing to several factors that decrease the viability of the bacterium during the isolation procedure or inadequate storage and transport of the gastric biopsy to the laboratory. Our work corroborated this observation, since $H$. pylori culture was the least effective method of the three used here. However, in 6 patients the only test that detected this bacterium was culture on artificial environment, showing that this methodology is also important as a diagnostic method. Besides, it provides the preservation of the strain for further studies [17].

The urease test (Clotest $\left.{ }^{\circledR}\right)$ was the most efficient method for the detection of $H$. pylori. The importance of this method is emphasized in the literature, which indicates the urease test as the invasive method of choice for $H$. pylori detection, with a sensitivity of 89\%-98\% and specificity of 93\%-98\% [18].

The detection of $H$. pylori by optical microscopy was also an efficient method. In two patients, the detection of $H$. pylori was only possible by this approach. This method is considered very important, since it provides a definite diagnosis of $H$. pylori infection and also of gastric inflammation, thus being important in the clinical diagnosis of gastritis [18]. In the study performed by Lobo Gatti and collaborators [19] the histological test was the most sensitive for $H$. pylori detection, compared to the urease and culture tests. All these factors emphasize the need of more than one method, for reliable detection of $H$. pylori.

In the present study, there was no difference in $H$. pylori infection rates between the genders corroborating other studies [20]. However, the prevalence of $H$. pylori was not higher in older patients, in contrast with data described in the literature [15,21,22]. The small number of patients aged between zero and nineteen enrolled in our study could explain this result. 
Table 2. H. pylori and its association with various clinical outcomes in the 172 patients studied

\begin{tabular}{|c|c|c|c|c|}
\hline \multirow[b]{2}{*}{ Clinical outcome } & \multirow[b]{2}{*}{ N (\% total) } & \multicolumn{3}{|c|}{$\mathrm{X}^{2}$ test with Yates } \\
\hline & & $\begin{array}{l}\text { With } H . \text { pylori } \\
\text { n1 }(\%)^{* *}\end{array}$ & $\begin{aligned} & \text { No H. pylori } \\
\text { n2 } & (\%)^{* *}\end{aligned}$ & Significance \\
\hline Gastritis & 52 (30\%) & 40 (77\%) & $12(23 \%)$ & $\begin{array}{l}\mathrm{p}=0.0633 ; \chi^{2}=3.44 \\
\text { not significant* }\end{array}$ \\
\hline Gastric Ulcer & 56 (33\%) & 55 (98\%) & $12 \%)$ & $\begin{array}{l}\mathrm{p}=0.0022 ; \chi^{2}=10.87 \\
\text { significant* }\end{array}$ \\
\hline Duodenal Ulcer & 48 (28\%) & 48 (100\%) & $0(0 \%)$ & $\begin{array}{l}\mathrm{p}=0.0018 ; \chi^{2}=11.32 \\
\text { significant* }\end{array}$ \\
\hline Peptic Ulcer & $103(60 \%)$ & 102 (99\%) & $1(1 \%)$ & $\begin{array}{l}\mathrm{p}<0.0001 ; \chi^{2}=35.35 \\
\text { significant* }\end{array}$ \\
\hline Intestinal Metaplasia & 15 (9\%) & 15 (100\%) & $0(0 \%)$ & $\begin{array}{l}\mathrm{p}=0.19 ; \chi^{2}=1.26 \\
\text { not significant* }\end{array}$ \\
\hline GERD & 32 (19\%) & $21(67 \%)$ & 11 (33\%) & $\begin{array}{l}\mathrm{p}=0.001 ; \chi^{2}=12.46 \\
\text { significant* }\end{array}$ \\
\hline Normal & $9(5 \%)$ & $4(44 \%)$ & $5(56 \%)$ & $\begin{array}{l}\mathrm{p}=0.0037 ; \chi^{2}=9.61 \\
\text { significant* }\end{array}$ \\
\hline Total & 172 (100\%) & 147 (85\%) & 25 (15\%) & $\longrightarrow$ \\
\hline
\end{tabular}

$\mathrm{N}$ : total number of patients with certain pathology; n1: number of $H$. pylori positive patients with certain disease; n2: number of $H$. pylori negative patients with certain pathology.; *: Statistical difference was accepted for $P=0.05$; **: Percentage of patients with certain disease that are H.pylori positive or negative. Some patients with GERD also exhibit pathologies in the stomach and were also considered in other groups.

No association was observed between the presence of $H$. pylori and the smoking habit. The literature data on this type of association are contradictory, what shows the need for further studies to reach a definitive answer to this question [23-25].

Alcohol ingestion is not considered a risk factor for $H$. pylori infection. Murray and collaborators [26], in a study conducted in Bristol, UK, showed the existence of an inverse correlation between alcohol ingestion and the presence of an active infection by $H$. pylori. However, in our work, no relation of this type was found between the habit of consuming alcoholic beverages and the presence of $H$. pylori. This observation was also previously reported [13].

The presence of $H$. pylori is described as being higher among the NSAID users than in people that do not used these medicines [13]. However, in our study, no such association was found.

When the prevalence of $H$. pylori was analyzed in relation to the ethnic backgrounds of the patients, grouped as Caucasians, Afro-descendants, Mulattos and Asians based on skin colors, no association was found. The number of Asian patients analyzed in our study was very small (only two patients), precluding any conclusion regarding $H$. pylori prevalence in this ethnic group.

A strong correlation between the presence of $H$. pylori and various gastric diseases has been described in several studies [reviewed by 3]. In the present study, H. pylori was not associated with gastritis (Table 2). On the other hand, our data suggest that ingestion of NSAID is associated with gastritis and erosive gastritis development, as well is the smoking habit with gastritis. Interestingly, an inverse correlation was found between alcohol beverages ingestion and gastritis development. This effect was only seen in men but this could be because a higher proportion of men ingested this type of beverage. As discussed before, we did not find a correlation between ingestion of beverages and $H$. pylori presence. However, we can not rule out an antagonist effect of alcohol ingestion on $H$. pylori density in the stomach mucosa. This antagonistic action could reduce the number of bacterial cells colonizing this organ reducing the inflammatory process.

The present study indicates a strong correlation between $H$. pylori infection and presence of peptic ulcer, in agreement with the data in the literature [reviewed by 3]. The ingestion of alcohol beverages increased the risk for peptic ulcer in men as indicated by the logistic regression analysis. We speculated that this effect is a consequence of the liberation of more acid secretions by the parietal cells, stimulated by alcohol ingestion [27], worsening the tissue damage caused by $H$. pylori. Thus, although alcohol beverages ingestion has a beneficial action on gastritis, an inverted effect is seen since more severe tissue damages leading to peptic ulcerations could develop. Therefore, we did not find a protective effect of alcohol ingestion on PUD development.

Published data is contradictory regarding the association between $H$. pylori infection and the presence of gastroesophageal reflux, such as esophagitis and Barrett's esophagus. Several authors [28-32] have shown that the $H$. pylori prevalence is lower in this type of disease. However, other studies [33,34] demonstrated that the eradication of $H$. pylori does not increase the risk of developing gastroesophageal reflux disease in all cases, indicating that 
the negative association between the presence of this bacterium and this disease is not universally true. In the present work, a greater proportion of patients with gastroesophageal reflux was observed within the group that was not colonized by $H$. pylori (Table 2), and the differences were significant. Thus, our study supports that $H$. pylori has a protective effect on GERD development.

In certain circumstances, chronic inflammation induced by $H$. pylori can induce the loss of the normal architecture of the gastric mucosa, leading to the substitution of epithelial gastric cells by intestinal metaplasic cells. People with intestinal metaplasia in their stomach exhibit a significant increase in the risk of developing gastric cancer [reviewed by 35]. The presence of intestinal metaplasic cells is described in the literature as being strongly associated with colonization by $H$. pylori [reviewed by 7]. On the contrary, our data did not support such conclusions.

\section{Acknowledgements}

We thank CNPq (Conselho Nacional de Desenvolvimento Científico e Tecnológico), FAPESP (Fundação de Amparo a Pesquisa do Estado de São Paulo) and FAEPA (Fundação de Apoio ao Ensino, Pesquisa e Assistência do Hospital das Clínicas da FMRP - USP) for financial support. During the course of this study, JL Proença-Módena was supported by a scholarship from CNPq. In addition, we thank everybody in the Endoscopy Service of the HCRP and everybody in the Genomics and Bacterial Molecular Biology Laboratory of the FMRP. We also thank Dr. Antonello Covacci (Chiron, Siena, Italy), Dr. CML Maffei and Dr. E Arruda (FMRP, USP) for many suggestions and scientific assistance and Rodrigo Tsai (UNICAMP) for assistance on the statistical analysis.

\section{References}

1. Dunn B.E., Cohen H., Blaser M.J. Helicobacter pylori. Clin Microbiol Rev 1997;10:720-41.

2. Covacci A., Telford J.L., Giudice G.D., et al. Helicobacter pylori virulence and genetic geography. Science 1999;284:1328-33.

3. Blaser M.J., Atherton J.C. Helicobacter pylori persistence: biology and disease. J Clin Invest 2004;113:321-33.

4. Blaser M.J., Parsonet J. Parasitism by the slow bacterium Helicobacter pylori leads to altered gastric homeostasis and neoplasia. J Clin Invest 1994;94:4-8.

5. Kurata J.H., Nogawa N.A. Meta-analysis of risk factors for peptic ulcer: Nonsteroidal anti-inflammatory drugs, Helicobacter pylori, and smoking. J Clin Gastroenterol 1997;24:2-17.

6. Perez-Perez G.I, Rothenbacher D., Brenner H. Epidemiology of Helicobacter pylori infection. Helicobacter 2004;9(Suppl 1):16.

7. Kuipers E.J, Blaser M.J. Helicobacter pylori and Gastroduodenal Disorders. In: Scheld W.M, Armstrong D., Hughes J.M. eds. Emerging Infections. Washington: ASM Press, 1998.

8. Ge Z., Taylor D.E. Contributions of genome sequencing to understand the biology of Helicobacter pylori. Annu Rev Microbiol 1999;53:353-87.

9. Alm R.A., Ling L.S., Moir D.T., et al. Genomic-sequence comparison of two unrelated isolates of the human gastric pathogen Helicobacter pylori. Nature 1999;397:176-80.
10. Salama N., Guillemin K., McDaniel T.K., et al. A whole-genome microarray reveals genetic diversity among Helicobacter pylori strains. Proc Natl Acad Sci U.S.A. 2000;97:1466873.

11. Heading R.C., Castell D.O. Clinical spectrum and diagnosis of gastroesophageal reflux disease. In: D.O. Castell, Richter J. E. eds. The Esophagus. Philadelphia: Lippincott Williams \& Wilkings, pp. 381-8, 2004.

12. Glupczynski Y. Culture of Heliobacter pylori from gastric biopsies and antimicrobial susceptibility testing. In: Lee A., Mégraud F. eds. Helicobacter pylori: techniques for clinical diagnosis \& basic research. London: W. B. Saunders Company Ltd, 1996.

13. Bani-Hani K.E., Hammouri S.M. Prevalence of Helicobacter pylori in Northern Jordan. Saudi Med J 2001;22:843-7.

14. Coelho L.G., Das S.S., Karim Q.N., et al. Campylobacter pyloridis in the upper gastrointestinal tract: a Brazilian study. Arq Gastroenterol 1987;24:5-9.

15. Almeida Cunha R.P., Alves F.P., Rocha A.M., et al. Prevalence and risk factors associated with Helicobacter pylori infection in native populations from Brazilian Western Amazon. Trans R Soc of Trop Med Hyg 2003;97:382-6.

16. Zuniga-Noriega J.R., Bosques-Padilla F.J., Perez-Perez G.I., et al. Diagnostic utility of invasive tests and serology for the diagnosis of Helicobacter pylori infection in different clinical presentations. Arch Med Res 2006;37:123-8.

17. Makristathis A., Hirschl A.M., Lehours P., Megraud F. Diagnosis of Helicobacter pylori infection. Helicobacter 2004;9(Suppl 1):7-14.

18. Cutler A.F., Havstad S., Ma C.K., et al. Accuracy of invasive and noninvasive tests to diagnose Helicobacter pylori infection. Gastroenterol 1995;109:136-41.

19. Lobo Gatti L., Agostinho J.N.F., De Lábio R., et al. Helicobacter pylori and cagA and vacA gene status in children from Brazil with chronic gastritis. Clin Exp Med 2003;3:166-72.

20. Castro L.P., Coelho L.G. Helicobacter pylori in South America. Can J Gastroenterol 1998;12:509-12.

21. Graham D.Y., Malaty H.M., Evan D.G., et al. Epidemiology of Helicobacter pylori in an asymptomatic population in the United States: effect of age, race and socioeconomic status. Gastroenterol 1999;100:1495-1501.

22. Rocha G.A., Rocha A.M., Silva L.D., et al. Transmission of Helicobacter pylori infection in families of preschool-aged children from Minas Gerais, Brazil. Trop Med Int Health 2003;8:987-91.

23. Rajashekhar V., Bhasin D.K., Ray P., et al. Helicobacter pylori infection in chronic smokers with non ulcer dyspepsia. Trop Gastroenterol 2000;21:71-2.

24. Ogihara A., Kikuchi S., Hasegawa A., et al. Relationship between Helicobacter pylori and smoking and drinking habits. J Gastroenterol Hepatol 2000;15:271-6.

25. Rosenstock S.J., Jorgensen T., Andersen L.P., Bonnevie O. Association of Helicobacter pylori infection with lifestyle, chronic disease, body-indices, and age at menarche in Danish adults. Scand J Public Health 2000;28:32-40.

26. Murray L.J., Lane A.J., Harvey I.M., et al. Inverse relationship between alcohol consumption and active Helicobacter pylori infection: the Bristol Helicobacter project. Am J Gastroenterol 2002;97:2750-5.

27. Khanna U.M., Abraham P. Determinants of acid secretion. $J$ Assoc Physicians India 1990;38:727-30.

28. Pakodi F., Abdel-Salam O.M., Debreceni A., Mozsik G. Helicobacter pylori. One bacterium and a broad spectrum of human disease! An overview. J Physiol Paris 2000;94:139-52.

29. Loffeld R.J., Werdmuller B.F., Kuster J.G., et al. Colonization of cagA-positive Helicobacter pylori strains inversely associated with reflux esophagitis and Barretts esophagus. Digestion 2000;62:95-9. 
30. Vaezi M.F., Falk G.W., Peek R.M., et al. CagA positive strains of Helicobacter pylori may protect against Barretts esophagus. Am J Gastroenterol 2000;95:2206-11.

31. Raghunath A., Hungin A.P., Wooff D., Childs S. Systematic review: the effect of Helicobacter pylori and its eradication on gastrooesophageal reflux disease in patients with duodenal ulcers or reflux oesophagitis. Aliment Pharmacol Ther 2004;20:733-44.

32. Beales I.L., Calam J. Interleukin 1 beta and tumour necrosis factor alpha inhibit acid secretion in cultured rabbit parietal cells by multiple pathways. Gut 1998;42:227-34.
33. Chiba N., Thomson A.B., Sinclair P. From bench to bedside to bug: an update of clinically relevant advances in the care of persons with Helicobacter pylori- associated diseases. Can J Gastroenterol 2000;14:188-98.

34. Vaira D., Vakil N., Rugge M., et al. Effect of Helicobacter pylori eradication on development of dyspeptic and reflux disease in healthy asymptomatic subjects. Gut 2003;52:1543-7.

35. Asaka M., Dragosics B.A. Helicobacter pylori and gastric malignancies. Helicobacter 2004;9(Suppl 1):35-41. 